\title{
Lições do Japão sobre energia nuclear
}

\author{
ROBERTO $\Upsilon$. HUKAI
}

$\mathrm{D}$ AQUI a mil anos, aO olhar pelo retrovisor, os historiadores sobre "energia nos séculos XX e XXI” certamente dirão que a história da energia nuclear foi muito fascinante. Esse especial fascínio da energia nuclear é bastante distinto do petróleo e do carvão que também merecerão capítulos importantes na história da energia.

Esse fascínio exercido pela energia nuclear, que a distingue do petróleo e do carvão, advém de dois aspectos de sua natureza que estão intimamente ligados com a psicopatologia do ser humano: o primeiro é derivado da possibilidade de o homem usar energia nuclear para matar maciçamente seus semelhantes; e o segundo é devido à psicoantropologia do medo (presente desde a infância) do inimigo invisível, obscuro, que eventualmente o poderia matar, a radiação nuclear.

Nos tempos do homem-primata, desde que ele inventou uma máquina capaz de matar um seu semelhante, ou um animal, a cem metros de distância, ele tanto se encantou com o arco-e-flecha que essa supermáquina foi admirada pelos guerreiros por milhares de anos, até a Idade Média. Logo no início dessa invenção, um "filósofo" daquela época teria pensado: "Nunca mais haverá guerras, pois o homem pode matar um inimigo a cem metros de distância...". Depois, o mesmo homem inventou a pistola, o canhão e outras coisas mais terríveis. Mas nada comparável a uma bomba termonuclear. Lembremos, "nunca mais haverá guerras...”.

Para ilustrar o poderio da energia nuclear como arma para matar seres humanos, imaginemos a explosão de uma bomba termonuclear de um megaton em cima de São Paulo, a mil metros de altura, sobre o túnel Nove de Julho. Primeiro, o calor resultante da explosão seria tão intenso (mais de 25 milhões de graus centígrados no seu centro) que quase todo material combustível pegaria fogo até a Serra da Cantareira, e a onda de choque do ar, seguido dos ventos na direção do talo do "cogumelo nuclear", teria uma força mecânica de arraste semelhante a um furacão de $300 \mathrm{~km} / \mathrm{h}$ na região de Santo Amaro. Um prédio de cinco andares receberia uma força lateral equivalente ao peso de mil elefantes, um sobre outro. Tudo isso resultaria na destruição dos prédios, na morte de mais de 1,6 milhão de paulistanos, logo nas primeiras horas. A massa dos gases radioativos (contendo, entre outros, os produtos de fissão Iodo-131, Césio 134/137 e Estrôncio-90), então, subiria a $400 \mathrm{~km}$ por hora para uma altura de 
uns $20 \mathrm{~km}$. E de lá, logo em seguida, esses gases radioativos seriam dispersos imediatamente sobre centenas de milhares de quilômetros quadrados na direção dos ventos sobre o Estado de São Paulo e o mar.

E, ao contrário do que se pensa, pouquíssimas pessoas morreriam de radiação nuclear direta! Os incêndios e as ondas de choque do ar seriam as causas de quase todas as mortes. Ou seja, numa explosão nuclear pouca gente morre de radiação. A grande maioria das vítimas morre pelos efeitos do calor e da força dos ventos sobre as edificações da cidade.

Por outro lado, no entanto, em um acidente nuclear da Classe 7 (IAEA) que venha a ocorrer em reatores nucleares de potência, uma grande massa de radioatividade seria lançada a uma altura de menos de 50 a 150 metros e, portanto, a radioatividade, dependendo das condições dos ventos no local, seria espalhada nas imediações do reator nuclear acidentado (10 a $30 \mathrm{~km}$ de raio, tipicamente). E, assim sendo, toda a população ao redor do reator acidentado (até $100 \mathrm{~km}$, em algumas manchas de terreno, como no caso de Fukushima) seria afetada pela radiação.

Num país densamente habitado, como o Japão, em que a população convive com os reatores de potência no mesmo espaço geográfico, a energia nuclear se torna inviável se se considerar a possibilidade de acidentes do tipo que ocorreu em Chernobyl.

De outra forma, devido à capacidade destrutiva das armas nucleares, o fator geopolítico sempre foi extremamente relevante na história da indústria nuclear. Daí decorrem fatos totalmente esdrúxulos para o senso comum. Por exemplo, um país pobre de somente 16 milhões de habitantes, como a Coreia do Norte, pode sentar-se numa mesa de negociações de igual para igual com países como os Estados Unidos, a China, a Rússia, o Japão e a Coreia do Sul, conjuntamente, para discutir o seu programa nuclear. Um outro caso esdrúxulo é o caso do Irã. Apesar de o país possuir a terceira maior reserva de gás natural do mundo, alega que procura desenvolver energia nuclear para geração de energia elétrica. Ora, qualquer estudante de pós-graduação em energia da USP sabe que uma usina de geração de energia elétrica feita com turbinas de combustão (turbinas a gás), utilizando o gás natural como combustível, requer cerca de cinco vezes menos investimento do que as usinas nucleares, e o seu custo de operação e manutenção também é mais baixo, sem contar os investimentos no desenvolvimento do ciclo do combustível nuclear.

O Japão seguiu os ensinamentos em engenharia nuclear do MIT, na década de 1960 (do qual fiz parte como aluno de pós-graduação), onde foi inventada a rota do Urânio-Plutônio, isto é, a contínua reciclagem do plutônio nos chamados Fast Breeder Reators (FBR), que possibilitaria ao Japão gerar energia elétrica durante "mil anos" com somente alguns navios carregados de urânio importado do exterior. $\mathrm{O}$ fato que mais fascinou os estudantes japoneses de engenharia nuclear era que a energia atômica gerada por um só quilograma de Urânio seria 
equivalente, em energia, a 52 vagões de carvão, de um trem de carga. Portanto, para os japoneses, somente um carregamento de navio com urânio importado poderia representar a independência energética de fontes externas. A lógica rota Urânio-Plutônio era a solução para o Japão se tornar independente de fontes externas de energia.

Desde então, o Japão se lançou, e persistiu no desenvolvimento do projeto dos Fast Breeder Reactors, que possibilitaria a reciclagem do plutônio gerado no reator, continuamente. Visitei o primeiro piloto de FBR, Joyo, e o início da construção do protótipo comercial, Monju, no início da década de 1980, em Tsuruga.

Mas o projeto do reator Monju se tornou uma tragédia monumental. Depois de mais de trinta anos, e custos de 1,2 trilhão de yens correntes, o projeto hoje está sendo abandonado, tendo operado somente um dia com os seus 280 MW nesses mais de trinta anos de sua história.

Monju Bodisatva, segundo o budismo, era um deus da iluminação e da sabedoria infinitas. De fato, Monju mostrou-se como o deus da sabedoria que ensinou os japoneses, pelo preço de mais de 20 bilhões de dólares, a abandonar o projetos dos FBR.

Esse programa do FBR japonês guarda algumas lições importantes. Os próprios Estados Unidos, a Inglaterra e a França abandonaram os esforços para desenvolver esse tipo de reator, depois de gastarem dezenas de bilhões de dólares. Os ensinamentos de Monju podem ser sintetizados no Ocidente pela Lei de Murphy, isto é, "tudo que pode dar errado, um dia acontece, e no pior momento". O refrigerador de sódio do reator Monju pegou fogo em 1995, depois de nove anos em construção. Como resultado, Monju ficou parado até 2010, quando, durante o processo de reativação do reator, dois operadores derrubaram um robô dentro do reator durante o carregamento de combustível nuclear. Dois operadores se suicidaram. Monju foi finalmente abandonado depois do acidente de Fukushima.

É digno de notar que a história da indústria nuclear japonesa, no que tange ao ciclo do combustível nuclear, também foi cheia de percalços. Em setembro de 1999, na usina de reprocessamento do combustível nuclear para a separação do plutônio, em Tokaimura, ocorreu um grave acidente no qual cerca de trezentos empregados foram contaminados por radiação e dois deles vieram a falecer. Mais tarde, a corporação PNC, dona da planta, veio a se desculpar em público por ter escondido a verdadeira dimensão e a gravidade daquele acidente.

A energia nuclear sofre de uma doença chamada de síndrome da mulher de César: "Não basta ela ser honesta, ela precisa parecer honesta". No caso de Fukushima, houve uma antítese dessa síndrome. A mulher de César realmente parecia honesta (com base na tecnologia e na disciplina japonesas), mas era uma vagabunda: havia um contínuo conluio entre os executivos dos maiores fabricantes de reatores do mundo, as concessionárias de eletricidade nuclear, e 
os reguladores-licenciadores. Conluio este moldado nas horas de folga nos spas urbanos de Tóquio entre os executivos dos três setores. Todos os três ramos da indústria nuclear japonesa se encontravam sob um mesmo ministério, quebrando-se a independência dos reguladores, regra básica da segurança nuclear. E aos executivos da Tokyo Electrial Power Company (TEPCO) interessava mais o preço das ações da TEPCO na Bolsa de Tóquio do que acidentes nucleares.

De fato, o acidente de Fukushima mostrou claramente que foi provocado pela "ignogância", ou seja, uma mistura de ignorância com arrogância dos executivos da indústria nuclear japonesa, nela incluídos funcionários do governo. $\mathrm{O}$ tsunami de Fukushima serviu somente como um fator ignitor do acidente nuclear. Certa vez, ouvi de uma das secretárias dos professores do Departamento de Engenharia Nuclear da Universidade de Tóquio o seguinte: "Mas, eles sempre nos ensinaram que os reatores nucleares japoneses eram seguros...".

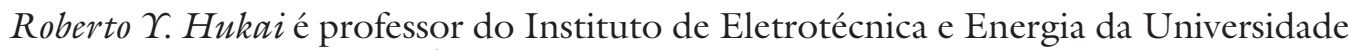
de São Paulo (IEE-USP). É doutor em Engenharia Nuclear pelo Massachusetts Institute of Technology (MIT), localizado em Cambridge, Massachusetts, nos Estados Unidos. @-ryhukai@gmail.com

Recebido em 29.5.2013 e aceito em 5.6.2013. 